\title{
EDUCAÇÃO DE SURDOS: Aspectos a se considerar segundo a percepção dos alunos de um Instituto Federal de Educação, Ciência e Tecnologia sobre sua inclusão em espaço acadêmico
}

EDUCACION PARA SORDOS: Aspectos a se considerar según la percepción de los estudiantes de un Instituto Federal de Educación, Ciência y Tecnología sobre su inclusion en un espacio académico

EDUCATION OF THE DEAF: Aspects to be considered according to the perception of the students of a Federal Institute of Education, Science and Technology about their inclusion in an academic space

César Gomes de Freitas ${ }^{1}$ https://orcid.org/0000-0002-0027-5528

Cristina Maria Carvalho Delou ${ }^{2}$ https://orcid.org/0000-0001-9206-6004

Tatiane Militão de Sá3 https://orcid.org/0000-0001-5675-6171

Helena Carla Castro 4 https://orcid.org/0000-0001-5283-1541

\section{Resumo}

O cenário da inclusão dos alunos surdos no ensino médio e superior ainda se encontra em construção e demanda avaliações constantes para adequação do atendimento acadêmico deste público. Este trabalho apresentou como objetivo uma investigação e análise da percepção dos alunos com deficiência sobre o atendimento recebido em um Instituto Federal da Rede Federal de Educação Profissional, Científica e Tecnológica. O público alvo escolhido foi os alunos surdos de um Instituto Federal da Região Norte do país, que ainda está em fase de implantação, com cinco anos

\footnotetext{
${ }^{1}$ Doutor em Ensino pelo Instituto Oswaldo Cruz da Fiocruz. Docente do Instituto Federal do Acre (IFAC). Email: cesar.freitas@ifac.edu.br

${ }^{2}$ Doutora em Educação. Docente Aposentada da Universidade Federal Fluminense. E-mail: cristinadelou@globo.com

3 Doutoranda em Ciências e Biotecnologia pela UFF. E-mail: tatimili2@yahoo.com.br

${ }^{4}$ Doutora em Química Biológica. Docente da Universidade Federal Fluminense (UFF). E-mail: hcastrorangel@yahoo.com.br
}

Como referenciar este artigo:

FREITAS, C. G.; DELOU, C. M. C.; SÁ, T. M.; CASTRO, H. C. Educação de surdos: Aspectos a se considerar segundo a percepção dos alunos de um Instituto Federal de Educação, Ciência e Tecnologia sobre sua inclusão em espaço acadêmico. Revista Pedagógica, v. 23, p. 1-22, 2021. 
de atividade, considerando nessa escolha que a deficiência surdez é aquela que se apresenta em maior proporção dentre os alunos com deficiência atendidos nesta Instituição. O trabalho utilizou uma abordagem quali-quantitativa e empregou questionários e entrevistas. Os resultados indicaram que apesar de satisfeitos com o atendimento recebido, os alunos percebem a existência de diversos problemas e preocupações, principalmente em relação ao despreparo de professores para o atendimento a este público, o que aponta para a necessidade de que se realize formação acadêmica dos professores tanto em nível superior quanto em pós-graduação em relação a esse tema.

Palavras-chave: Educação de surdos, inserção em espaço acadêmico, Institutos Federais.

\title{
Resumen
}

El escenario de la inclusión de estudiantes sordos en la educación media y superior aún se encuentra en construcción y demanda constantes evaluaciones para ajustar la asistencia académica de este público. Este trabajo tuvo como objetivo investigar y analizar la percepción de estudiantes con discapacidad sobre la atención recibida en un Instituto Federal de la Red Federal de Educación Profesional, Científica y Tecnológica. El público objetivo elegido fueron los estudiantes sordos de un Instituto Federal de la Región Norte del país, que aún se encuentra en fase de implementación, con cinco años de actividad, considerando en esta elección que la deficiencia de sordera es la que se presenta en mayor proporción entre los estudiantes. con discapacidad atendidos en esta institución. El trabajo utilizó un enfoque cualitativo y cuantitativo y utilizó cuestionarios y entrevistas. Los resultados indicaron que a pesar de estar satisfechos con el servicio recibido, los estudiantes perciben la existencia de varios problemas e inquietudes, especialmente en relación a la falta de preparación de los docentes para atender a esta audiencia, lo que apunta a la necesidad de una formación académica para los estudiantes. profesores de nivel superior y posgrado en relación con este tema.

Palabras clave: Educación para sordos, inserción en el espacio académico, Institutos Federales

\begin{abstract}
The scenario of the inclusion of deaf students in secondary and higher education is still under construction and demands constant assessments to adequacy the academic attendance of this public. The objective of this work was to investigate and analyze the perception of students with disabilities about the care received at a Federal Institute of the Federal Professional, Scientific and Technological Education Network. The target audience was the deaf students of a Federal Institute of the Northern Region of the country, which is still in the implantation phase, with five years of activity, considering in this choice that the deafness deficiency is the one that presents in greater proportion among the students with disabilities at this institution. The work used a qualitativequantitative approach and used questionnaires and interviews. The results indicated that, although satisfied with the attendance received, students perceive the existence of several problems and concerns, mainly in relation to the lack of preparation of teachers for the attendance to this public, which points to the need for academic training of the students. professors at both higher and postgraduate levels in relation to this topic.
\end{abstract}

Keywords: Deaf education, insertion in academic space, Federal Institutes.

\section{INTRODUÇÃO}


A inclusão de alunos com deficiência na escola não é tarefa simples, pois as dificuldades do ensino-aprendizado de estudantes com surdez são acentuadas pela dificuldade de comunicação, conforme Lima (2010, p. 118): “A audição é um sentido fundamental para a maioria das pessoas, afinal, o ouvido é um canal importante para receber informações do mundo externo". A surdez é a perda total ou parcial, congênita ou adquirida, da capacidade de compreender a fala por intermédio do ouvido e pode comprometer significativamente o aprendizado e os aspectos cognitivos, se as pessoas afetadas não tiverem um atendimento educacional direcionado as suas necessidades específicas (ORRÚ, 2012).

O ensino de alunos com surdez não é um tema simples nas escolas. Segundo Cruz e Araújo (2016, p. 382): “A educação das pessoas com surdez tem sido um assunto muito polêmico nos últimos anos, marcada por conflitos e controvérsias".

O fato de os estudantes com surdez constituírem um grupo heterogêneo, com diferentes necessidades educacionais específicas, ampliam as dificuldades das instituições de ensino ( $\mathrm{COOL}$ et al, 2004). Afirmações que possam ser simplesmente generalizadas a todos os alunos surdos contribuem para dificultar, pois impedem que informações específicas e realísticas atinjam os profissionais que atendem esse público. Exemplos da diversidade que envolve os alunos surdos incluem o nível de letramento quanto ao português escrito e a adoção ou não da leitura labial, além do nível de entendimento da Língua Brasileira de Sinais (Libras). Isto demonstra que as discussões sobre o ensinoaprendizado dos estudantes com surdez devem levar em consideração a necessidade de reconhecer e respeitar as características das pessoas surdas.

Conforme indicam Fernandes e Orrico (2012, p. 105):

A acessibilidade em relação à pessoa surda não pode deixar de ser refletida a partir do estigma e preconceito que a Língua Brasileira de Sinais e a cultura surda sofreu durante anos de supremacia de um modelo centrado no ouvinte, tanto nos espaços dos sistemas oficiais educacionais e inclusive no campo acadêmico.

Tendo em vista a legislação atual que garante o uso da Libras como primeira língua pelos surdos em nosso país, a comunicação desses se baseia na Língua de Sinais que faz parte de toda uma cultura que se mantém graças às associações destas pessoas. A Libras pode e deve auxiliar na construção da identidade pessoal dos surdos, devendo ser 
conhecida por todos, incluindo professores e colegas ouvintes, já que é uma das línguas oficiais do país. (COOL et al., 2004)

Causa preocupação estudos sobre a educação dos alunos surdos, como o realizado por Mendes (2006, p. 399) que revelam que, quando matriculados em salas comuns, “mesmo para as poucas matrículas existentes, faltam aspectos básicos para garantir não apenas o acesso, mas a permanência e o sucesso desses alunos". Esse cenário então demanda constante avaliação e ajuste para o adequado atendimento desse público com a garantia do acesso ao ensino previsto em lei com presença de intérpretes e ambiente bilíngue (MARTINS; SOUSA, 2013; MOURA, 2013).

Atualmente o desafio da inclusão está presente na Rede Federal de Educação Profissional, Científica e Tecnológica do Brasil. A Rede é constituída por 38 institutos, com mais de 400 unidades que oferecem cursos gratuitos do nível médio até o pósdoutoramento (REDE, 2013). A grande abrangência e importância devido a sua capacidade de formar cidadãos habilitados e preparados para a vida profissional faz com que um perfil inclusivo na forma de divulgação seja determinante para contribuir com o aumento dos índices de formação de pessoas com deficiência e garantia de acesso aos seus direitos.

No intuito de manter a sua missão, o Instituto Federal de Educação, Ciência e Tecnologia (IFECT) da região Norte em análise neste estudo, começou as suas atividades acadêmicas a partir de 2010, para aproximadamente 350 discentes matriculados em nove cursos dos eixos de Recursos Naturais, Ambiente, Saúde e Segurança e Gestão e Negócios, distribuídos em quatro campi. Atualmente, o IFECT oferece Cursos de Formação Inicial e Continuada de Trabalhadores, Cursos Técnicos de Nível Médio nas formas integradas ao ensino médio e subsequente, Cursos Técnicos de nível médio modalidade EJA com o programa PROEJA, Cursos Superiores de Tecnologia, além de Programas, como Mulheres Mil, CERTIFIC E PRONATEC.

Baseado na perspectiva do ensino para todos, realizamos neste trabalho um estudo de caso, investigando e analisando as condições de atendimento aos estudantes surdos oferecidas pelo respectivo Instituto Federal (IFECT), um dos Institutos da Rede Federal brasileira, no sentido de identificar pontos a serem melhorados na perspectiva institucional e dos professores no ensino técnico-profissional para o público com surdez do IFECT e de servir de orientação para outros institutos federais, pois, conforme relata Lima (2010, p. 
56): “Torna-se necessário estimular as instituições a efetuarem verificaçõos periódicas, visando alcançar de fato a acessibilidade para todos".

O objetivo deste trabalho foi realizar uma investigação e análise das percepções dos estudantes surdos de um Instituto Federal da região Norte do país em relação ao atendimento oferecido pela instituição ao público surdo, considerando que a Instituição ainda está em fase de implantação, mas já trabalhando na perspectiva da inclusão e procurando contribuir com esse cenário acadêmico de formação.

Para isso, este artigo está relacionado da seguinte forma: na próxima seção, apresentamos a metodologia adotada no levantamento dos dados utilizados para pesquisa e, em seguida, apresentamos os resultados e a discussão.

\section{MATERIAIS E MÉTODOS}

Este trabalho utilizou a abordagem quali-quantitativa que empregou questionários (contendo questões fechadas, abertas e semiabertas) além de entrevista com roteiro semiestruturado como forma de avaliação (CAREGNATO; MUTTI, 2006), envolvendo aspectos como metodologia de ensino dos professores, atendimento oferecido, dificuldades existentes, entre outros.

O Instituto Federal escolhido localiza-se em um Estado da Região Norte, pois com cinco anos de funcionamento, considera-se relevantes suas atividades na perspectiva da inclusão que oferece atendimento a alunos surdos em uma instituição recém-implantada.

Após a aprovação do Comitê de Ética e Pesquisa do Instituto Oswaldo Cruz da Fiocruz, parecer $n^{\circ}$ 644.846, a pesquisa foi realizada entre agosto e novembro de 2015 quando foram aplicados, junto ao termo de livre consentimento esclarecido, um questionário contendo 12 (doze) questões a todos os estudantes surdos dos três campi do referido Instituto, aplicado em o auxílio dos intérpretes de Libras do referido campus.

Além dos questionários quantitativos, foram realizadas entrevistas com todos os participantes da pesquisa, novamente com o auxílio de intérpretes que possibilitaram, além de novas informações e esclarecimentos, uma análise qualitativa por meio de questões que emergiram no contexto das entrevistas, conforme discutido na literatura (PATTON, 1980 apud COHEN et al., 2001). 
Neste contexto, também participaram da pesquisa os coordenadores do Núcleo de Atendimento às Pessoas com Necessidades Específicas (NAPNE) de todos os campi do referido Instituto, no sentido de tentar comprovar a percepção dos alunos frente ao que é realmente oferecido pela instituição.

A presente pesquisa se iniciou com a análise dos registros dos NAPNEs dos quatro campi do IFECT, destes apenas três possuíam alunos com surdez à época da pesquisa. Assim, após coletados os dados das entrevistas e questionários aplicados foram divididos três temas estabelecidos para análise de dados dos atendimentos sendo a percepção dos surdos: no ambiente acadêmico, suas categorias administrativas e de infraestrutura; nos cursos superiores e técnicos; nos aspectos de impacto sobre os fatores pedagógicos os quais abordaremos na sessão resultados e discussão.

\section{RESULTADOS E DISCUSSÃO}

Dos três campi analisados, somente o primeiro mantinha os registros e dados tanto dos atuais alunos como daqueles que evadiram de seus respectivos cursos. $\mathrm{O}$ segundo campus só dispunha de informações sobre os atuais educandos, sem informações sobre os que se evadiram, enquanto o terceiro campus ainda iniciava atividades com os dois primeiros alunos surdos inseridos com matriculas ativas. O total de estudantes surdos participantes da pesquisa foi de doze (12). Dessa forma, apresenta-se a seguir os temas definidos para a análise dos dados neste intento.

2.1 Atendimento aos alunos surdos no ambiente acadêmico do IFECT, categorias administrativas e de infraestrutura.

Considerando o primeiro tema, nos três campi estudados, verificou-se potencial de análise para o campus que possuía os dados completos. Salientamos que neste os registros iniciaram no ano de 2012 e que durante o período da pesquisa havia um total de doze alunos, conforme figura 1 a seguir. 
REVISTA

Figura 1 - Número de alunos registrados no campus em ambiente acadêmico

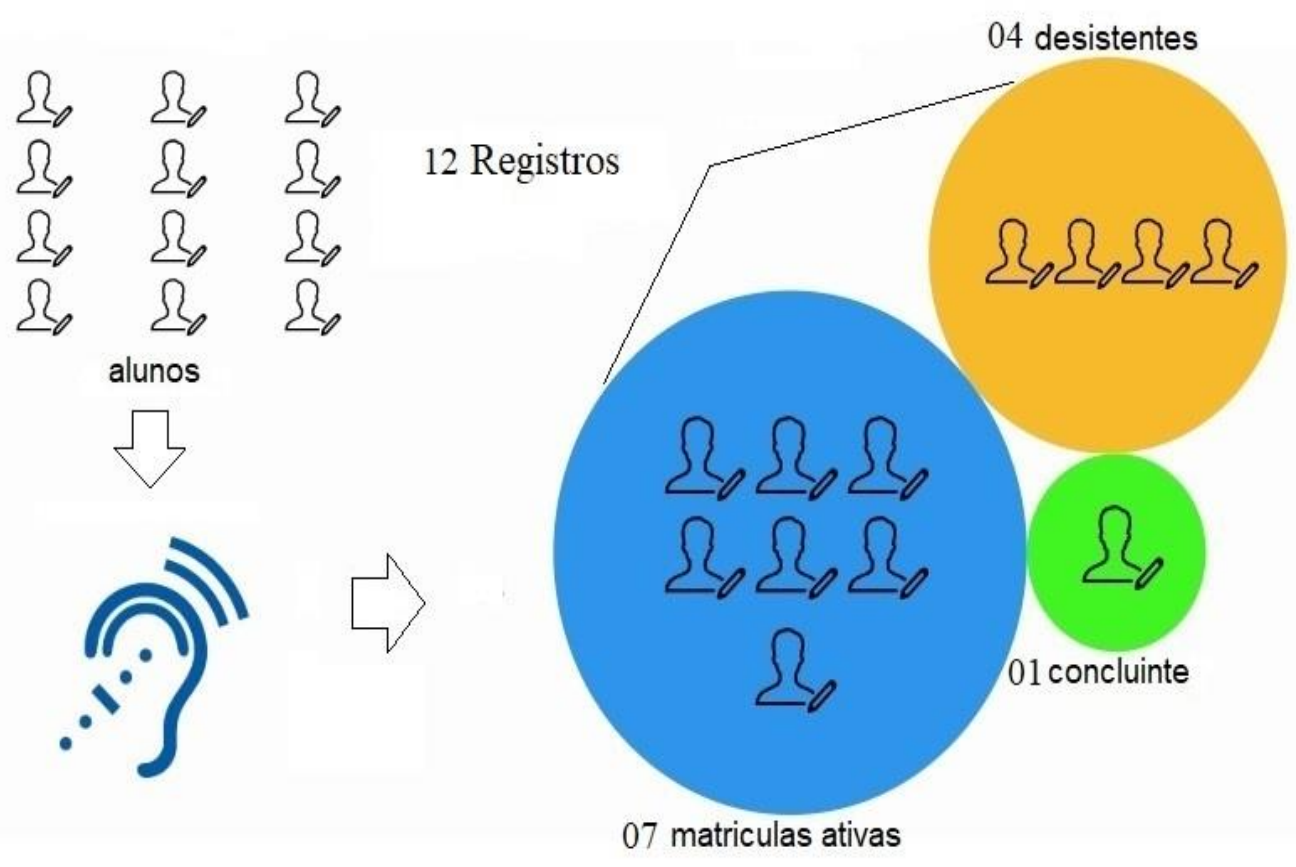

Fonte: Dados da pesquisa (2020)

Nas entrevistas realizadas a maioria relatou (gráfico 1) que conhecera o IFECT por meio da Internet e comunidade surda e somente quatro alunos afirmaram obter informações por meio da família, amigos e outros cursos realizados naquela Instituição.

Gráfico 1 - Abordagem de como os alunos conheceram o IFECT

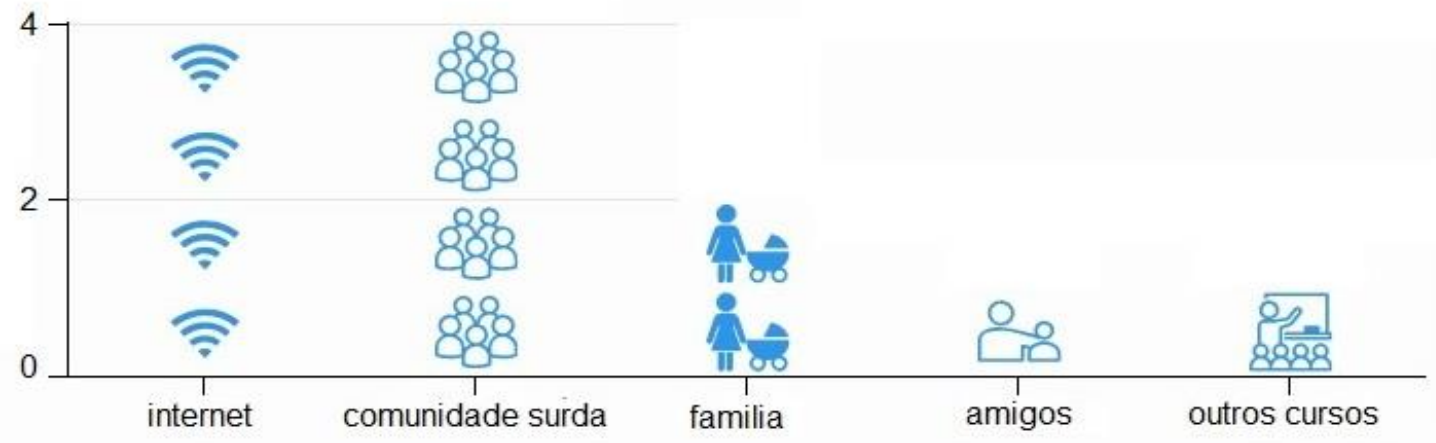

Fonte: Dados da pesquisa (2020)

Conforme, Rosa e Cruz (2001, p. 52), a internet oferece aos surdos subsídios para que eles se conheçam e integrem na realidade sócio-político-cultural de seu meio. Neste 
REVISTA

Revista do Programa de Pós-Graduação em Educação da Unochapecó

ISSN 1984-1566 (on-line) ISSN 1415-8175 (impressa)

caso, acredita-se que o poder de interação da comunidade surda através de vídeos é extremamente alto o que em potencial reflete nos dados do gráfico 1.

Quando questionados sobre a vida escolar anterior e se acreditavam que houve inclusão por parte dos professores, equipe gestora e colaboradores das escolas na qual estudaram, $75 \%$ dos alunos responderam positivamente. Aqueles que responderam negativamente justificaram sua resposta em razão da falta de interpretes, falta de estrutura e falta de interesse por parte da escola na qual estudou.

Sobre a inserção nos cursos do IFECT observa-se (figura 2) que os alunos frequentavam os seguintes cursos: Superior em Tecnologia de Processos Escolares (dois alunos); Técnico em Segurança do Trabalho (três alunos); Técnico em Administração (três alunos); Técnico em Manutenção e Suporte de Informática (dois alunos); Técnico em Informática (um aluno) e Técnico em Recursos Humanos (um aluno).

Figura 2 - Matrículas de alunos inseridos em diversos cursos do IFECT

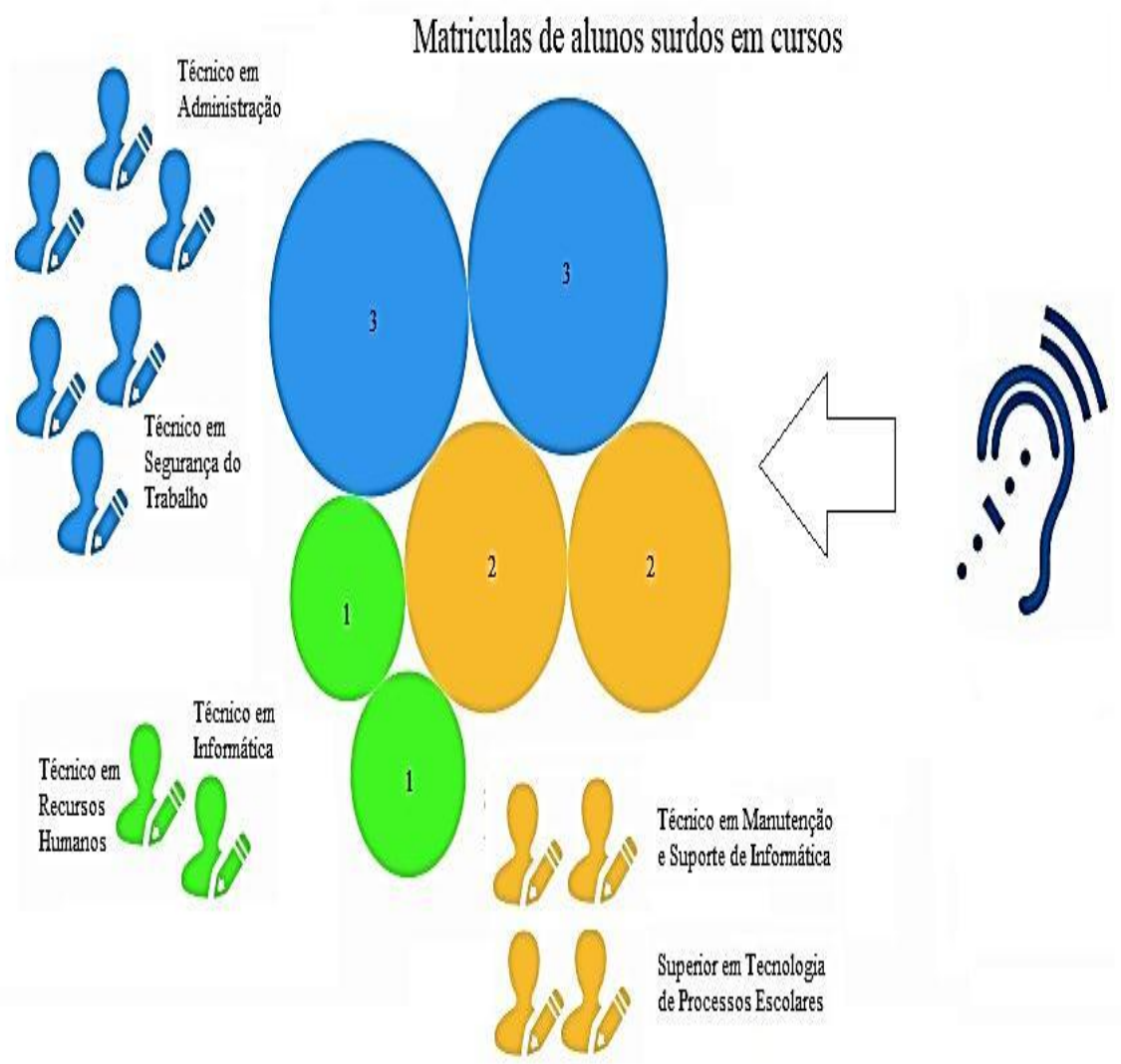

Fonte: Dados da pesquisa (2020) 
REVISTA

Revista do Programa de Pós-Graduação em Educação da Unochapecó

ISSN 1984-1566 (on-line) ISSN 1415-8175 (impressa)

De acordo com os dados da inserção nos cursos do IFECT, pode-se destacar as matriculas em nível superior com censo da Educação Superior (BRASIL, 2016), para um total de 8.052.254 de alunos matriculados nos 34.366 cursos de graduação foram que ofertados em 2.407 instituições de educação superior (IES) no Brasil, dos quais 0,45\% são estudantes com deficiência, transtornos globais do desenvolvimento ou altas habilidades/ superdotação dos quais as matriculas em 2015, quando comparadas ao ano de 2016 tiveram o maior crescimento (0,2\%), como observamos na Tabela 1.

Tabela 1 - Inclusão na Educação Superior

Matrícula na educação superior de alunos com deficiência, transtornos

globais do desenvolvimento ou altas habilidades/superdotação

Brasil 2009-2016

\begin{tabular}{c|c|c}
\hline Ano & $\begin{array}{c}\text { Alunos matriculados com deficiência, } \\
\text { transtornos globais do desenvolvimento ou } \\
\text { altas habilidades/superdotação }\end{array}$ & $\begin{array}{c}\text { Percentual em } \\
\text { relação ao total } \\
\text { de matrículas na } \\
\text { graduação }\end{array}$ \\
\hline 2009 & 20.530 & 0,34 \\
\hline 2010 & 19.869 & 0,31 \\
\hline 2011 & 22.455 & 0,33 \\
\hline 2012 & 26.663 & 0,38 \\
\hline 2013 & 29.221 & 0,40 \\
\hline 2014 & 33.475 & 0,43 \\
\hline 2015 & 37.986 & 0,47 \\
\hline 2016 & 35.891 & 0,45 \\
\hline
\end{tabular}

Fonte: Censo Educação Superior MEC/Inep, (2018) ${ }^{5}$

\footnotetext{
${ }^{5}$ Inclui alunos matriculados em Cursos de graduação e Sequencial de Formação Específica; um mesmo aluno pode ter mais de um tipo de deficiência, transtornos globais do desenvolvimento ou altas habilidades/superdotação.
} 
REVISTA

Revista do Programa de Pós-Graduação em Educação da Unochapecó

ISSN 1984-1566 (on-line) ISSN 1415-8175 (impressa)

Conforme Bisol et al. (2010, p. 02), a maior presença de estudantes surdos em contextos universitários é recente, e deriva de diversos fatores, entre os quais: o reconhecimento da Língua Brasileira de Sinais; as propostas de educação bilíngue para surdos; e os momentos de políticas públicas vêm aos poucos aumentando o acesso e a participação ativa de pessoas com necessidades especiais em diferentes contextos sociais. Considera-se as duas matriculas em nível de grau acadêmico dos alunos do IFECT um reflexo dos contextos universitários atuais, conforme gráfico 2.

Gráfico 2 - Evolução de alunos com deficiência matriculados nos cursos de graduação

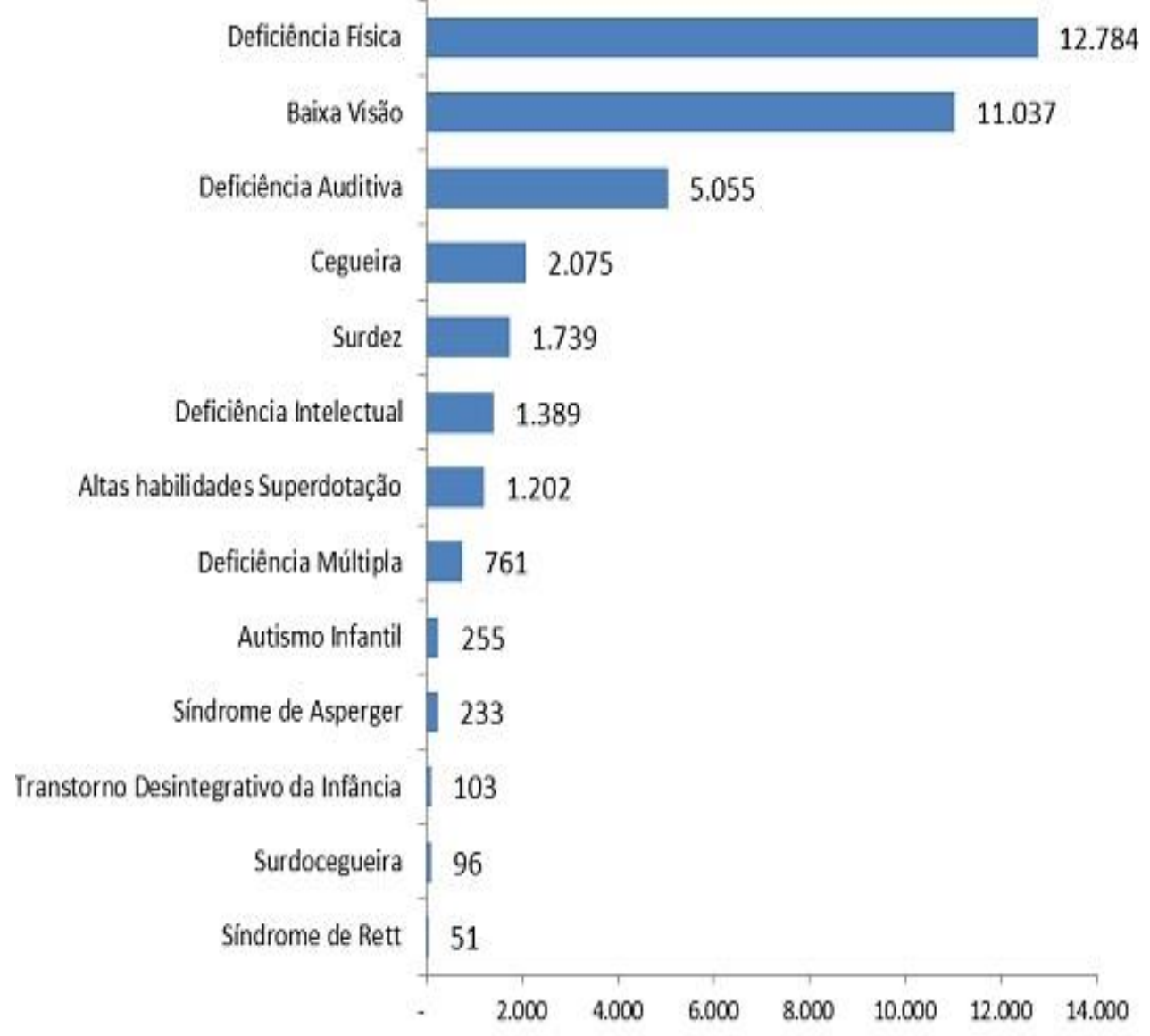

Fonte: Censo Educação Superior MEC/Inep, 2016

Segundo Kebach, Carminatti e Paaz (2011, p. 549), explicam que esses índices são animadores; entretanto, cabe ponderar que a elevação do número de matrículas não se deve à transformação da cultura universitária, mas às ações afirmativas de projetos 
especiais do MEC em universidades, inclusive para a implementação dos cursos de licenciatura específica de Letras/Libras, em 18 universidades públicas brasileiras.

Porém, o maior números de matriculas da Instituição se deu em nível técnico, considera-se um fator importante no caso dos cursos ofertados pela Escola Técnica de acordo com Santos e Santos (2016, p. 7), "é a tradição que se consolidou em torno desses cursos sob concepções de trabalho" o que pode implicar sobremaneira nas potenciais escolhas dos alunos para inserção no mercado, uma vez que, neste campi (figura 2) há inclusão de 10 alunos em cursos de nível técnico comparado ao nível superior, representam aproximadamente $90 \%$ dos participantes da pesquisa.

Dessa forma, observa-se que a inserção destes alunos implica na relação de perspectivas que tinham ao chegar ao IFECT, de forma geral todos demonstraram ter, a época do ingresso, expectativas positivas quanto ao Instituto. As respostas deixaram claro que todos buscavam crescimento e mudar sua trajetória de vida, por meio de maior facilidade em entrar no mercado de trabalho.

De acordo com Terra e Gomes (2013), os jovens ficam ansiosos sobre a inserção no ambiente de trabalho. Assim, verifica-se na pesquisa que três dos participantes relataram sentir esta mesma ansiedade para estudar, buscar informações e aprender os conhecimentos necessários para ter condições de entrar no mercado de trabalho.

Outrossim, se declina às coordenações de NAPNEs, uma vez que, entre os dados analisados ocorreram informações sobre alta rotatividade destes profissionais o que representa um fator problema para o IFECT, pois segundo Freitas e colaboradores (2005, pag. 771): “a rotatividade, além de ser prejudicial ao andamento e desenvolvimento dos trabalhos, impede o aumento da confiança dos alunos com deficiência nos coordenadores dos NAPNEs", sendo que as mantém maior organização e controle de informações são aquelas cujos coordenadores estão a mais tempo exercendo a função.

Há ainda relatos de outras dificuldades como, por exemplo, a questão da infraestrutura que foi citada por quatro dos participantes, que apontaram a necessidade de melhorias, tais como a criação de sala de recursos multifuncional - SRM. Salienta-se a importância da SRM, ambiente que auxilia na interação e aprofundamento de conteúdos interdisciplinares nas salas de aula inclusivas. Conforme legislação pertinente "as salas de recursos multifuncionais são ambientes dotados de equipamentos, mobiliários e materiais 
didáticos e pedagógicos para a oferta do atendimento educacional especializado". (BRASIL, 2010, p. 5).

No entanto, mesmo com relatos sobre a inexistente SRM nos campi daquele Instituto, todos os participantes responderam positivamente ao serem questionados sobre acessibilidade em relação a suas necessidades educacionais específicas no IFECT. Considera-se que provavelmente ponderou-se a disponibilização de interpretes de Libras, pois segundo Martins e Napolitano (2017, p. 111), entende-se que o direito ao acesso à educação superior pressupõe reconhecer as necessidades de políticas públicas dirigidas ao reconhecimento da Libras e a valorização da presença do professional tradutor-intérprete de Língua de Sinais.

\subsection{O atendimento dos alunos surdos nos cursos superiores e técnicos do IFECT}

Em relação aos primeiros anos de estudo dos alunos nos cursos superiores e técnicos do IFECT, segundo as respostas, sempre foram estudantes de escolas públicas, o que correspondendo ao padrão do público atendido por aquele Instituto, em sua maioria estudantes oriundos de escolas públicas. Oliveira, Moreira e Silva (2014, p. 04), corroboram com a ideia de que os alunos optam por universidades públicas ao invés das faculdades particulares, mostrando a importância que as Instituições de Ensino Superior federais e estaduais têm no papel de formação do profissional brasileiro.

Os participantes dos cursos, quando questionados sobre se sentirem incluídos (figura 3), $66 \%$ responderam positivamente, enquanto $34 \%$ dos alunos surdos do IFECT não se sentiam plenamente incluídos. Esse é um índice significativo que sinaliza a necessidade de aprimoramento no atendimento destinado a este público, para que haja o sentimento de pertencimento que é discutido por vários autores como Smith (2008), Lima (2010) e Orrú (2012).

Figura 3: Percepção dos alunos surdos do IFECT sobre a inclusão nos cursos 
REVISTA

Revista do Programa de Pós-Graduação em Educação da Unochapecó

ISSN 1984-1566 (on-line) ISSN 1415-8175 (impressa)

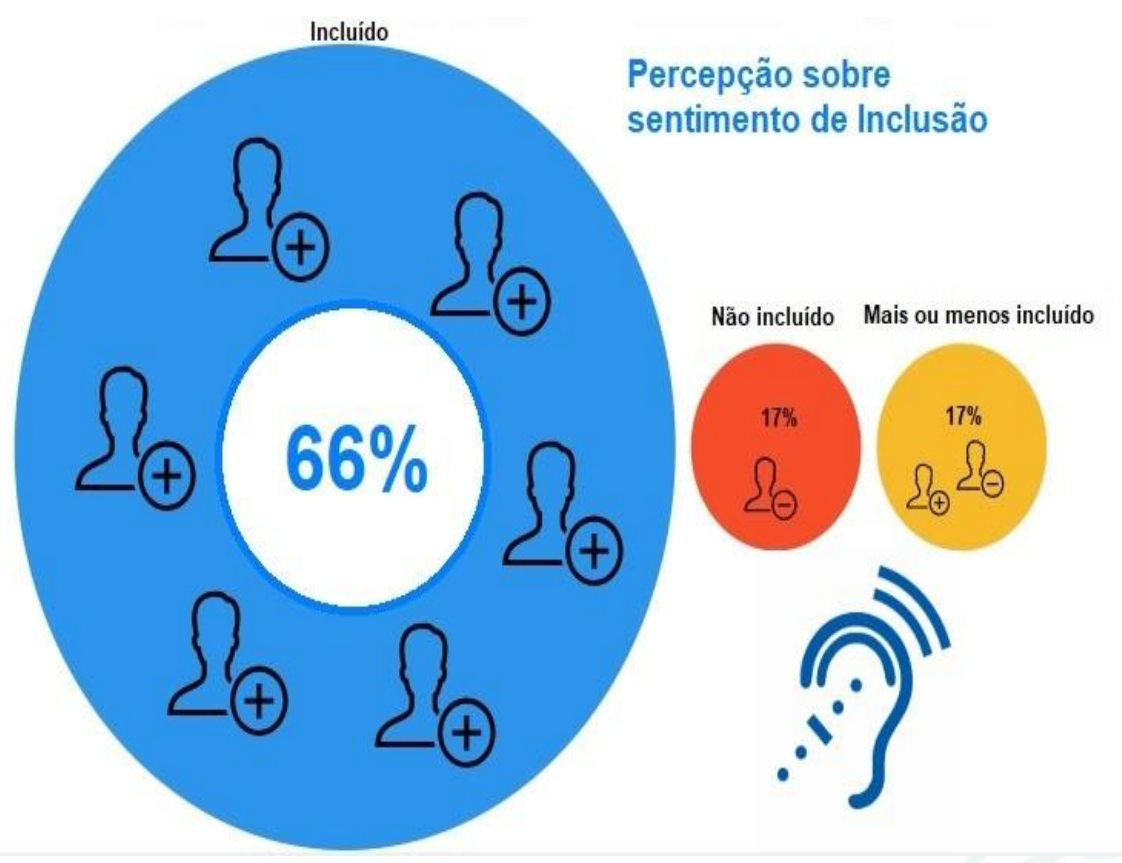

Fonte: Dados da pesquisa (2020)

Sobre a forma de tratamento recebido pelos colegas, $75 \%$ sentiam-se tratados da mesma forma que os demais colegas e aqueles que responderam negativamente indicaram como justificativa a existência de preconceito por parte dos colegas em relação a eles.

No entanto, os dados desta pesquisa apontam que quando questionados sobre o que falta para o IFECT ser de fato uma Instituição inclusiva, a maioria das respostas (gráfico 3), versou sobre a necessidade de capacitar os professores em Língua Brasileira de Sinais Libras para melhorar a comunicação com os alunos surdos.

Gráfico 3 - Opinião dos alunos em relação a necessidade de os professores aprenderem Libras para efetiva inclusão 


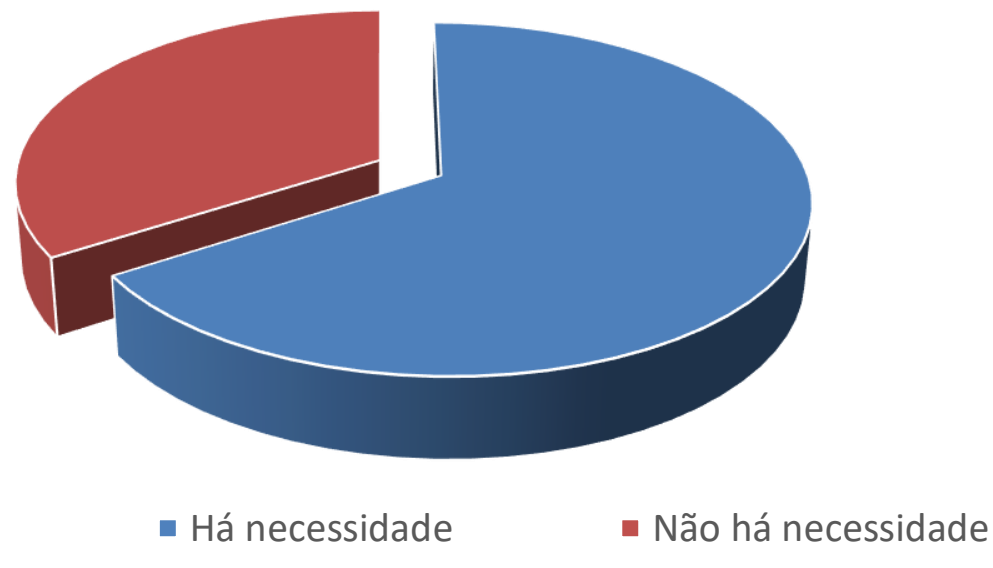

Fonte: Dados da pesquisa (2020)

Salientamos que dos $66 \%$ que declaram se sentirem incluídos positivamente no Instituto revela-se em igual indicie a falta da capacitação em Libras de forma negativa conforme figuras 3 e 4 , observa-se neste contraponto uma inclusão parcial que se confunde com uma inclusão efetiva, uma vez que, de acordo com COOL e colaboradores (2004), a restrição e desconhecimento da Língua de Sinais torna a comunicação entre ouvintes e surdos difícil e caracterizada pelo isolamento do sujeito surdo, geralmente em minoria em ambiente educacional inclusivo. Entende-se que a configuração desse cenário pode comprometer inclusive não só as questões de socialização dos alunos surdos, mas também sua estabilidade sócio emocional, levando por vezes a evasão dos mesmos.

Ressalta-se neste estudo que os interpretes não estariam atendendo plenamente a demanda acadêmica destes alunos a contento, fazendo com que estes queiram que os professores saibam Libras e não mais necessitem exclusivamente da atuação e desempenho dos interpretes contratados. Autores como COOL et al. (2004), relatam que a performance dos interpretes pode ser comprometida não só pela ausência de formação na área específica da disciplina, bem como pela falta de interação prévia com o professor e a ausência de sinais sobre temas específicos.

Considera-se aqui que a maior parte das justificativas realizadas remete as dificuldades para entender a explicação dos professores durante as aulas sempre acessadas via interpretes que geralmente não tem formação na área ou em áreas 
correlatas ou afins. Novamente o desconhecimento de Libras parece ser o fato que contribui para a percepção dos alunos do não atendimento as suas demandas acadêmicas.

Para Silva e Rodrigues (2011, p.62), a inclusão educacional compreende a produção e complexidades na realidade de cada indivíduo é um processo que demanda disposição e compromisso no sentido de contribuir para formação do sujeito social. Neste quesito observa-se que há complexa tensão na relação entre professor- aluno surdo e a presença de um intérprete de Libras/ Língua Portuguesa no IFECT devido à barreira na comunicação tornando compreensível a afirmação de lacunas que resultam na realidade deste indivíduo como sujeito social.

\title{
2.3 Aspectos de impacto sobre os fatores pedagógicos
}

Para desenvolver a temática dos aspectos de impacto sobre os fatores pedagógicos analisa-se em especial a relação dos alunos com os professores, pois uma das características do IFECT é possuir professores das mais variadas formações, muitos dos quais vindos de cursos de bacharelado, sem os conhecimentos específicos sobre Educação Especial e Inclusiva, conhecimentos estes que estão presentes nos diversos cursos de licenciaturas. Sobre o papel dos professores na Educação Especial e Inclusiva, Caiado (2011, p. 143) faz considerações importantes:

\begin{abstract}
A literatura sobre Educação Inclusiva tem apontado que as atitudes dos professores face aos alunos com deficiência inseridos em suas salas de aulas depende de muitos fatores, entre eles, do tipo de sociedade em que se insere a escola, das concepções e representações sociais relativas à deficiência, à diferença, à diversidade, às dificuldades de aprendizagem; e dos recursos e mecanismos de financiamento das escolas. Todos esses aspectos representam na nossa realidade, razoáveis desafios e cabe ressaltar a priori que a mudança na formação dos professores, embora seja uma condição necessária e essencial, não será suficiente para a Educação Inclusiva se concretize em nosso país.
\end{abstract}

Ainda sobre o papel dos professores, Terra e Gomes (2013, p. 117) relatam: “A inclusão escolar implica, efetivamente, um aprimoramento constante dos professores, com a apresentação de instrumentos e referenciais que evoluam e desenvolvam as práticas pedagógicas aplicadas por eles”. Essa reflexão reforça a necessidade de se rever a formulação do ensino superior e de pós-graduação na formação de futuros docentes. 
REVISTA

Revista do Programa de Pós-Graduação em Educação da Unochapecó

ISSN 1984-1566 (on-line) ISSN 1415-8175 (impressa)

De acordo com Soares e Carvalho (2012), sobre o professor e o aluno com deficiência aborda que deve ser item de preocupação uso de adaptações metodologias por parte destes profissionais, revelando necessidade de capacitação e treinamento de todos para melhor atendimento deste público, com o desenvolvimento de estratégias adequadas para tal.

Em relação à metodologia e didática para atender as expectativas e necessidades dos surdos verifica-se na figura 4, que estes informaram que tais adaptações simplesmente não acontecem. Neste aspecto a maioria (figura 5) registrou que os professores não fazem adaptações necessárias em suas apresentações em sala, como, por exemplo, a utilização de mais imagens e figuras para facilitar o entendimento dos assuntos abordados, tornando difícil entender as explicações durante as aulas.

Figura 4 - Expectativas e necessidades visuais dos alunos

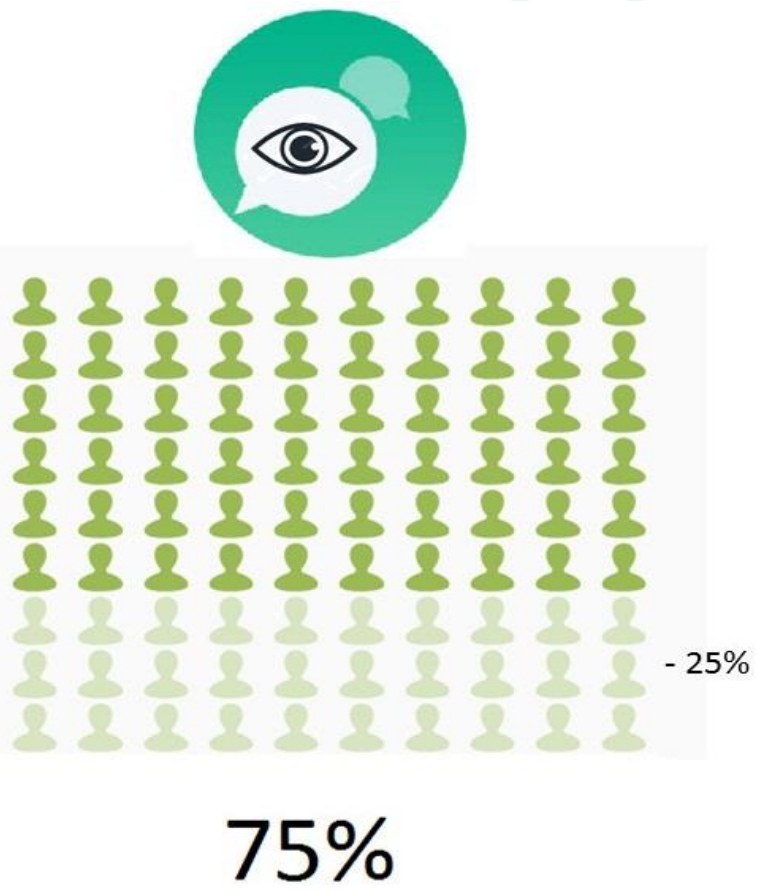

Reclamam a utilização de maior número de imagens e figuras para facilitar o entendimento dos conteúdos abordados. 
Na Educação Inclusiva, Lima (2010) afirma que o ensino do público surdo demanda o uso de imagens que usa o principal canal de aprendizagem destes alunos, a visão. Contudo, já se sabe que a adaptação do material didático com o aumento da imagética atende não só aos surdos, considerando que a visão é o sentido também de grande importância para os ouvintes.

Segundo Carvalho et. al (2017, p. 10), a inclusão dos alunos Surdos requer superar alguns obstáculos, necessitando de mudanças no sistema educacional e uma adaptação no currículo, sendo necessárias alterações nas formas de ensino, com garantias iguais às do aluno ouvinte.

Conforme afirma Rumberger (2006), estes obstáculos são caracterizados como desafios, processos que se articulam em favor da diminuição de registros de alunos desistentes e/ou que trancam suas matriculas, causando a evasão escolar por meio de duas perspectivas: visão do aluno e instituições.

Observa-se também em outras pesquisas (QUADROS, 2006; CAMPELLO, 2007; LACERDA, 2013) que a permanência do surdo com matriculas ativas em escolas dependem de diversos fatores como: metodologias adequadas, capacitação de professores em Libras, atuação de intérpretes com sinais específicos e outros.

Estes resultados ratificam a possível falta de capacitação e treinamento e da opinião dos participantes da pesquisa que relataram perceber ausência da dedicação dos professores em relação a suas deficiências.

As percepções destes alunos auxiliam e/ou contribuem para reduzir o processo de evasão escolar, a implementação de práticas pedagógicas visuais e estimular a capacitação de professores, formação continuada de interpretes de Libras em prol de uma efetiva inclusão nos espaços acadêmicos de instituições que prestam atendimento educacional especializado.

\section{CONSIDERAÇÕES FINAIS}

Sabe-se que os desafios do atendimento aos estudantes com surdez se encontram presentes em todas as Instituições de Ensino do Brasil que possui leis que visam garantir a esses alunos a sua cidadania e o seu acesso à educação. 
Por este motivo considera-se que as características e peculiaridades do atendimento foram abordados aqui como desafios segundo percepção dos alunos, tais como: a importância da utilização da primeira língua, Libras, em sala de aula com surdos, verificação de situações cujo ausência de sinais específicos de diversos temas acadêmicos dificulta o trabalho de interpretação/ tradução do intérprete e estratégias metodológicas diferenciadas.

Considera-se ainda que a maioria dos alunos nesta pesquisa foram recorrentes à temática capacitação de professores em relação a necessidades educacionais específicas o que aponta para urgência de investimentos em cursos de formação e capacitações relacionados a alunos com deficiência e/ou surdos, Libras e outros.

Assim, este trabalho colabora com outras pesquisas e apresenta aspectos importantes sobre Educação de surdos em um Instituto Federal no Brasil a serem observados por instituições de ensino superior que atenda este público, reforçando que intentos que se declinam sobre este objeto são continuamente necessários para busca de informações aos problemas relacionados a inserção de surdos em espaços escolares segundo percepção dos alunos.

\section{REFERÊNCIAS}

BRASIL. MEC/ INEP. Instituto Nacional de Pesquisas Educacionais Anísio Teixeira. Sinopse estatística da educação superior: censo 2015. Brasília, DF: O Instituto, $2015 a$.

BRASIL. MEC/ INEP. Instituto Nacional de Pesquisas Educacionais Anísio Teixeira. Sinopse estatística da educação superior: censo 2016. Brasília, DF: O Instituto, 2016b.

BRASIL. MEC/ INEP. Instituto Nacional de Pesquisas Educacionais Anísio Teixeira. Sinopse estatística da educação superior: censo 2017. Brasília, DF: O Instituto, 2017c.

BRASIL. Ministério da Educação (MEC). Secretaria de Educação Especial. Manual de Orientação: programa de implantação de sala de recursos multifuncionais. Brasília: MEC/Secretaria de Educação Especial, 2010. 33 p. Disponível em: <http://www.oneesp.ufscar.br/orientacoes_srm_2010.pdf>. Acesso em: 20 out. 2018.

BISOL, C. A. et al. Estudantes surdos no nível superior: reflexões sobre a inclusão.

Cadernos de Pesquisa, v. 40, n. 139, p.147-172, jan./abr. 2010. Disponível em: http://www.scielo.br/pdf/cp/v40n139/v40n139a08 Acesso em: 15 abr. 2018. 
Revista do Programa de Pós-Graduação em Educação da Unochapecó ISSN 1984-1566 (on-line) ISSN 1415-8175 (impressa)

CAIADO, K.; JESUS, D.M. de.; BAPTISTA, C.R. (Organizadores). Professores e educação especial: formação em foco. Porto Alegre: Edição/CDV/FACITEC, 2011.

CAREGNATO, R.C. A; MUTTI, R. Pesquisa qualitativa: análise de discurso versus análise de conteúdo. Texto \& Contexto- Enfermagem, v.15, n.4, p.679-84, 2006.

CARVALHO, C. C. et al. Evasão escolar de alunos surdos: por que não intervir ao invés de criticar? In: IV Congresso Nacional de Educação, CONEDU. João Pessoa (PB) 15 a 17 nov. 2017.

CAMPELLO, A.R. S. Pedagogia Visual/Sinal na Educação dos Surdos. QUADROS, R.M; PERLIN, G. (Orgs.), Estudos Surdos II. Petrópolis, RJ: Arara Azul, 2017, p. 100-131.

COHEN, L; MANION, L; MORRISON, K. Research Methods in Education. 5. ed. Inglaterra: Editora Routledge Falmer, 2001.

COOL, C.; MARCHESI, A.; PALACIOS, J. (Org.). Desenvolvimento psicológico e educação: transtornos do desenvolvimento e necessidades educativas especiais. 2. ed. Porto Alegre: Artmed, 2004.

CRUZ, S. R; ARAÚJO, D. A. C. A história da educação de alunos com surdez: ampliação de possibilidades. Revista Educação Especial, Universidade Federal de Santa Maria, v. 29, n. 55, p. 373-384, out/dez, 2016.

DEUS, V. O. Libras: uma língua estrangeira? Revista Arara Azul. v. 22, 2017. Disponível em: http://editora-arara-azul.com.br/site/admin/ckfinder/userfiles/files/3\%C2\%AA\%20 Artigo\%20 Viviane\%20Oliveira\%20 de\%20Deus.pdf Acesso em: 20 dez. 2017.

FERNANDES, E. M.; ORRICO, H. F. Acessibilidade e inclusão social. 2. ed. Rio de Janeiro: Descubra, 2012.

FREITAS, C. G.; DELOU, C. M.; CASTRO, H. C. Alunos com deficiência: investigação e análise das condições de atendimento de um Instituto Federal de Educação, Ciência e Tecnologia no Brasil. Revista Educação Especial. v. 28. n. 53, set./dez. 2015.

GUERREIRO, E.M.B.R. A acessibilidade e a educação: um direito constitucional como base para um direito social da pessoa com deficiência. In: Revista Educação Especial, Universidade Federal de Santa Maria, v. 25, n. 43, p. 217-232, maio/ago, 2012.

KEBACH, P.; CARMINATTI, J. S.; PAAZ, A. Experiência inclusiva no ensino superior: ações do núcleo de apoio psicopedagógico de uma instituição de ensino superior. In ANAIS de evento $1^{\circ}$ Seminário Luso-Brasileiro, 2017.

LACERDA, C.B. F.; ALBRES, N. A.; DRAGO, S.L.S. Política para uma educação bilíngue e inclusiva a alunos surdos no município de São Paulo. Educação e Pesquisa, p. 65-80. 


\section{REVISTA}
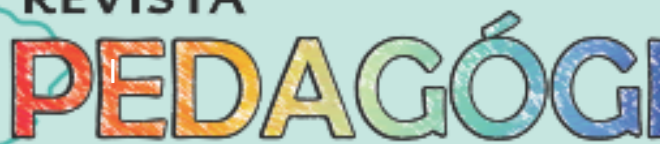

Revista do Programa de Pós-Graduação em Educação da Unochapecó

ISSN 1984-1566 (on-line) ISSN 1415-8175 (impressa)

LIMA, P. A. Educação inclusiva: indagações e ações nas áreas da educação e da saúde. São Paulo: Avercamp,2010.

MARTINS, S. E. S. O.; NAPOLITANO, C. J. Inclusão, acessibilidade e permanência: direitos de estudantes surdos à educação superior. Educar em Revista, Curitiba, Brasil, v. 33, n. especial 3, p. 107-126, dez. 2017

MARTINS, D. A.; SOUSA, S. F. Educação infantil e aquisição da linguagem: contrapontos de uma política inclusiva e bilíngue para surdos. In: ALBRES, N.A.; NEVES, S.L.G. (Org.). Libras em estudo: política educacional. São Paulo: FENEIS, 2013. p.71-96.

MAZZOTTA, M.J.S. Educação Especial no Brasil: histórias e políticas públicas. 6. ed. São Paulo: Cortez, 2011.

MENDES, E. G. A radicalização do debate sobre inclusão escolar no Brasil. Revista Brasileira de Educação, v. 11, n. 33, set./dez. 2006.

MOURA, M.C. Surdez e Linguagem. In: LACERDA, C.B.F.; SANTOS, L.F. (Org.). Tenho um aluno surdo, e agora? Introdução a Libras e educação de surdos. São Carlos: EDUFSCar, 2013. p.13-26.

OLIVEIRA, S. R. G.; MOREIRA, F. R. C.; SILVS, F. F. M. Perfil e expectativa dos alunos concluintes dos cursos técnicos integrados do IFRN, Campus Apodi. HOLOS, A 30, V. 5 , 2014.

ORRÚ, S. E. Estudantes com necessidades especiais: singularidades e desafios na prática pedagógica inclusiva. Rio de Janeiro: Wak Editora, 2012.

QUADROS, R.M. Políticas linguísticas e educação de surdos em Santa Catarina: espaço de negociações. Cadernos Cedes, 2006. p. 141-161.

ROSA, A. S.; CRUZ, C. C.; CORDEIRO, A. S. R. C. Internet: fator de inclusão da pessoa surda. Rev. Online da Bibl. Prof. Joel Martins, Campinas, v.2, n.3, p.38-54, jun. 2001.

REDE FEDERAL DE EDUCAÇÃO PROFISSIONAL, CIENTÍFICA E TECNOLOGICA. Histórico da Rede Federal de Educação Profissional, Científica e Tecnológica. Brasília: MEC, 2013. Disponível em: <http://www.redefederal.mec.gov.br>. Acesso em: 23 mar. 2015.

RUMBERGER, R. W. Why students drop out of school. In G. Orfield (Ed.), Dropouts in America: Confronting the graduation rate crisis (2006, pp.131-155). Cambridge: Harvard Education Press.

SANTOS, D.S.; SANTOS, M. K. N. Instituto Federal de Educação, Ciência e Tecnologia de São Paulo e o direito a uma escola pública de qualidade: um estudo sobre perfil dos jovens estudantes ingressantes no Ensino Médio Técnico Integrado. In: Anais do III Colóquio Nacional, Eixo Temático I - Políticas em educação profissional, 2016. 
SOARES, M. A. L.; CARVALHO, M. F. O professor e o aluno com deficiência. São Paulo: Cortez, 2012.

TERRA, R. N.; GOMES C. G. Inclusão escolar: carências e desafios da formação e atuação profissional. Revista Educação Especial, Universidade Federal de Santa Maria, v. 26, n. 45, p. 109-124, jan/abr. 2013.

Enviado em: 08-06-2020

Aceito em: 02-12-2020

Publicado em: 01.02.2021 